\title{
Neuroeducación con enfoque militar y acciones contra el acoso $y$ abuso sexual en centros educativos
}

\section{Neuroeducation with a military focus and actions against sexual harassment and abuse in schools}

\author{
MSc, Medardo Renán Sarchi Sarchi ${ }^{1}$ \\ cenemilecuador2@hotmail.com
}

Recibido: 1/12/2017, Aceptado: 1/02/2018

\begin{abstract}
RESUMEN
La educación como proceso social que contribuye al bienestar de la comunidad tiene en su haber velar por la integridad y buen funcionamiento en los planteles educativos. La educación es un elemento variable en las sociedades pues se ve expuesta desde épocas remotas a constante cambio y transformación; por lo que el docente y facilitador requiere de amplia capacidad de adaptación, entonces se produce el surgimiento de diversas: teorías, estrategias, metodologías y prácticas que dependen de los resultados que se presentan en las y los estudiantes que forman parte del sistema educativo dentro de su proceso de aprendizaje. La Neurodidáctica o Neuroeducación se enfrenta a un obstáculo que consiste en cómo lograr que el cerebro del estudiante se encuentre en condiciones de aprender y al mismo tiempo pueda poner en práctica lo aprendido, de tal manera que se vea beneficiado a sí mismo y al entorno que lo rodea, por lo tanto, este fue el punto de partida de diversas investigaciones que llegaron a conclusiones interesantes.
\end{abstract}

Palabras clave: Neuroeducación, cerebro, aprendizaje, acoso, abuso sexual

\section{ABSTRACT}

Education as a social process that contributes to the well-being of the community has to ensure the integrity and proper functioning of educational facilities. Education is a variable element in societies because it is exposed from remote times to constant change and transformation; so the teacher and facilitator requires ample capacity for adaptation, then the emergence of diverse: theories, strategies, methodologies and practices that depend on the results that are presented in the students who are part of the education system within their learning process. Neurodidactic or Neuroeducation faces an obstacle that is how to make the student's brain able to learn and at the same time be put into practice what has been learned, in such a way

\footnotetext{
${ }^{1}$ Centro de Nivelación Educativa Militar "Cenemil"
} 


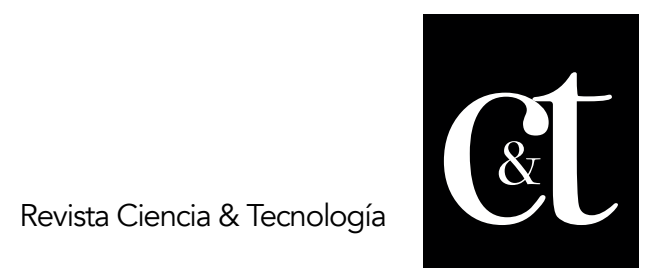

No. 18, 30 de abril de 2018

ISSN impreso: 1390 - 6321

that it benefits both the self and the environment it surrounds it, therefore, this was the starting point of various investigations that reached interesting conclusions.

Keywords: Neuroeducation, brain, learning, harassment, sexual abuse

\section{Introducción}

No cabe duda de que, la educación es un elemento variable en las sociedades pues se ve expuesta desde épocas remotas a constante cambio y transformación; por lo que el docente y facilitador requiere de amplia capacidad de adaptación, entonces se produce el surgimiento de diversas: teorías, estrategias, metodologías y prácticas que dependen de los resultados que se presentan en las y los estudiantes que forman parte del sistema educativo dentro de su proceso de aprendizaje.

Es así como, entre tantas opciones aplicables en busca de la mejora del proceso de enseñanza aprendizaje, surge la Neuroeducación, la misma que considera, en primer lugar, el estudio del cerebro y su influencia en la adquisición de nuevos conocimientos que sean perdurables para la persona que los adquiere.

Estos conocimientos no deben ser considerados únicamente desde el punto de vista teórico; sino también desde la perspectiva de lo práctica, aquello que al aplicarse puede derivar en consecuencias positivas para las y los estudiantes, en el caso de estudio; la Neuroeducación puede considerarse como una estrategia efectiva para la fomentación de valores y principios que permitan al niño, niña y adolescente reaccionar ante el embate de situaciones que pueden terminar en acoso y abuso sexual.

\section{Desarrollo}

Al analizar lo dicho, parece lógico que, si se quiere buscar un método que mejore la adquisición de conocimientos, se debe comenzar estudiando aquel órgano que es el centro de esta actividad, siendo sin duda este el cerebro.

Al respecto, González en su Tesis Doctoral "Neuroeducación y lingüística: una propuesta de aplicación a la enseñanza de la lengua materna" dice que: "...el cerebro, aun cuando es mucho lo investigado y descubierto del mismo ha mostrado ser un verdadero enigma de modo tal que parece ser muchas veces menor lo conocido todavía hoy ante todo lo que nos falta por conocer" (González Tapia, 2016).

De lo expuesto se puede definir que la investigación del cerebro es muy amplia, pero, los resultados son cada vez más impresionantes, demostrando que conforme se descubren nuevas características del cerebro, este se hace más enigmático e inexplorado.

La Neuro didáctica o Neuroeducación se enfrenta a un obstáculo que consiste en cómo lograr que el cerebro del estudiante se encuentre en condiciones de aprender y al mismo tiempo pueda poner en práctica lo aprendido, de tal manera que se vea beneficiado a sí mismo y al entorno que lo rodea, por lo tanto, este fue el punto de partida de diversas investigaciones que llegaron a conclusiones interesantes.

En primer lugar, se determinó que el cerebro presenta una característica conocida como plasticidad cerebral. En efecto, como señalaba García (2017): "El cerebro es "plástico", es decir, tiene una gran capacidad de adaptación durante toda la vida. Además, es capaz de crear constantemente nuevas neuronas y conexiones entre ellas 


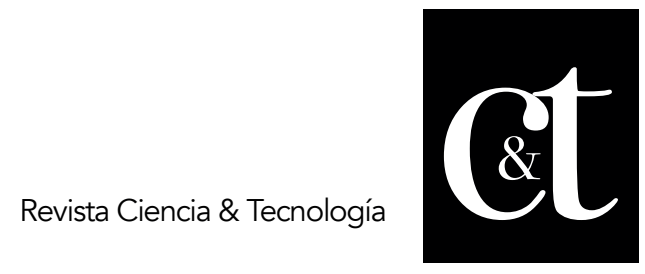

No. 18, 30 de abril de 2018

ISSN impreso: 1390 - 6321

si se le provee de la estimulación adecuada".

Con lo expuesto se quiere decir que el cerebro es un órgano humano que puede adaptarse a diferentes realidades, también es necesario reconocer que es capaz de crear nuevas neuronas y conexiones que permiten el aprendizaje; sin embargo, es necesaria la estimulación a lo largo de la vida, porque sin ella, los estudiantes se convierten en muros que no interiorizan lo que se les enseña.

En los estudios realizados, también se identificaron las neuronas espejo, las mismas que se caracterizan por ser células cerebrales que se activan cuando realizamos cualquier acción, pero también lo hacen cuando observamos a alguien más realizarla, también ocurre lo mismo con las expresiones emocionales; es decir, se aprende por ejemplos que se ve alrededor; sobre la base de las neuronas espejo se desarrollan situaciones como la empatía y la adquisición del lenguaje.

Otro elemento importante que se debe considerar en el aspecto de neuroeducación tiene que ver directamente con las emociones, las mismas que pueden intervenir de manera positiva o negativa en la gestión del aprendizaje. Este es el elemento más importante para el proyecto que está siendo planteado, pues, desde este punto de vista, se puede aprovechar el enfoque neuro educativo para enseñar a las y los estudiantes a ser conscientes de sus sentimientos y tomar el control de estos con una correcta conducta.

Esto nos indica que debe lograrse la correcta gestión de emociones, de tal manera que el aprendizaje logrado provoque emociones, lo cual trae como consecuencia que las adolescentes y los adolescentes aprendan mejor y de una manera permanente; es decir, alcanzando el aprendizaje significativo.

Desde hace dos décadas las Neurociencias aportan con nuevos conocimientos acerca del sistema nervioso y el cerebro, desde diferentes aspectos estructurales y funcionales que, al mismo tiempo han facilitado la comprensión acerca del proceso de aprendizaje.

Las investigaciones dejan resultados sorprendentes: "Las investigaciones utilizando neuroimágenes viabilizaron mayor conocimiento sobre las funciones cerebrales superiores y complejas, como el lenguaje, la memoria y la atención, las cuales son estimuladas, fortalecidas y evaluadas día tras día en los centros educativos de todo el mundo" (Campos, 2010).

Al analizar lo expuesto se puede afirmar que gracias a las Neurociencias se tiene un conocimiento más amplio de las funciones cerebrales en las que se incluyen elementos de gran importancia para el aprendizaje, como es el caso del lenguaje, la memoria y atención, lo cual después de haber expuesto a experimentación, se ha comprobado que al ser estimulados permiten alcanzar los aprendizajes significativos.

El proceso de enseñanza aprendizaje se ve inmerso en un conjunto de varios factores que incluyen el desarrollo de capacidades: cognitivas, sociales, emocionales, morales y físicas; las mismas que con ayuda del facilitador deben ser: aprendidas, desarrolladas, practicadas y utilizadas en el desenvolvimiento cotidiano.

La neuroeducación se caracteriza porque busca precisamente motivar al cerebro, para que este se encuentre en condición de constante aprendizaje y desarrollo; conforme 


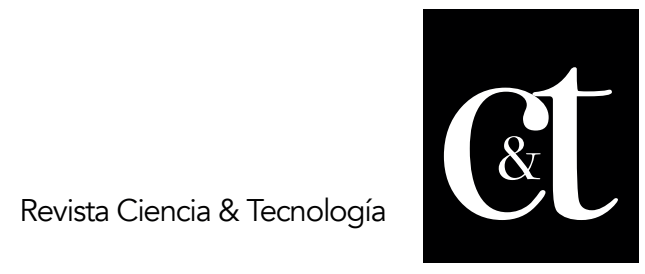

No. 18, 30 de abril de 2018

ISSN impreso: 1390 - 6321

el conocimiento del cerebro avance, el docente podrá efectivizar el proceso de enseñanza - aprendizaje, logrando una educación significativa tanto para el docente como para la y el estudiante.

Al definir que el aprendizaje se concentra principalmente en el cerebro, es necesario establecer que se debería vincular el estudio del órgano central del sistema nervioso con el desarrollo de estrategias educativas; tal como lo diría Gerhard Preiss en 1988: "De acuerdo con esta nueva disciplina, la pedagogía escolar y la didáctica general tienen que conceder más importancia al hecho de que el aprendizaje se basa en procesos cerebrales y que los resultados cognitivos se amplían paralelamente al desarrollo del cerebro infantil. Sobre esa base, la Neuro didáctica investiga las condiciones bajo las que el aprendizaje humano puede optimizarse al máximo" (Paterno, 2015).

Lo anterior permite determinar que la Neuro didáctica investiga las condiciones necesarias para que se produzca el aprendizaje, considerando como base primordial los procesos cerebrales que deben activarse para lograr que los objetivos de la enseñanza se cumplan de manera efectiva y de forma gradual que es lo adecuado.

Los diferentes estudios que se han realizado dejan como conclusión que cada cerebro humano es único y particular, aunque la estructura fisiológica es similar en todos los casos, lo cual conduce a una conclusión. Es necesario considerar la diversidad del estudiantado, pero, el facilitador en todos los casos necesita cumplir con el objetivo de enseñanza; inclusive se requiere de tomar en cuenta los trastornos del aprendizaje.

Otro factor que también se debe considerar dentro de la neurociencia es que, además del aspecto fisiológico, el ser humano se encuentra plagado de emociones que influyen sobre el aprendizaje. Al respecto se dice que: "La neurociencia ha demostrado que las emociones mantienen la curiosidad, nos sirven para comunicarnos y son imprescindibles en los procesos de razonamiento y toma de decisiones, es decir, los procesos emocionales y los cognitivos son inseparables" (Damasio, 2006). Por lo tanto, puede asumirse que las emociones tienen un papel fundamental en el desarrollo de procesos cognitivos pues despiertan la curiosidad, lo cual trae como consecuencia que los aprendizajes tengan una permanencia duradera para el aprendiz.

Es entonces necesario, buscar las estrategias y técnicas de enseñanza adecuadas para que las y los estudiantes activen su cerebro, aprendan y vinculen esos datos a sus emociones; de tal manera que estos dejen huella en su comportamiento y desenvolvimiento cotidiano. Entonces aquí es cuando los investigadores demostraron que el cerebro aprende por medio de patrones que detecta, aprende y de los cuales encuentra sentido; la dificultad está en activar el cerebro para que este tenga necesidad de aprender.

Precisamente la solución para la dificultad planteada radica en las emociones que rodean al sujeto de aprendizaje; expresadas a través de estímulos de tipo emocional que llevan a la curiosidad; aunque también pueden producirse emociones de tipo negativo que pueden frenan el impulso de aprendizaje.

Entonces, el objetivo de estudiar el cerebro y su interrelación con el aprendizaje consiste en encontrar los estímulos adecuados que provoquen cambios necesarios 


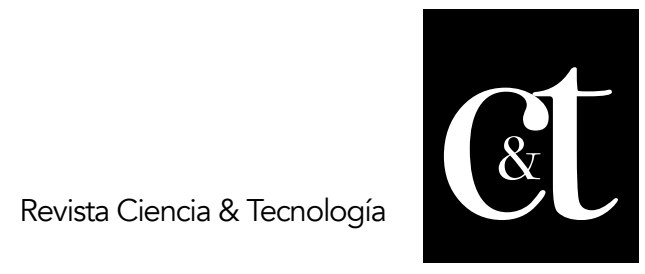

No. 18, 30 de abril de 2018

ISSN impreso: 1390 - 6321

para que la parte emocional de los individuos se anteponga a la parte racional, pero predisponga al estudiante hacia situaciones de aprendizaje.

Es necesario que se repita que lo que permite que el proceso de aprendizaje se inicie es la emoción que despierta curiosidad o interés, esto se logra a través de un sistema de recompensas que pueden ir desde un caramelo en los niños y las niñas hasta la satisfacción de haber logrado un reto en las y los estudiantes de años superiores.

Otro elemento importante para la implementación de la neuroeducación consiste en la memoria que puede ser de dos tipos:

Cuando una experiencia entra al cerebro, se deconstruye' y se distribuye por todo el córtex. El afecto (o contenido emocional) se almacena en la amígdala, las imágenes visuales en los lóbulos occipitales, la fuente de donde proviene el recuerdo en los lóbulos frontales y el lugar donde la persona estaba cuando almacenó la experiencia en los lóbulos parietales.

Cuando se recuerda la información, se tiene que reconstruir. Así que, entre más formas empleen los estudiantes para representar la información en su cerebro, tendrán, así mismo, más formas para reconstruir sus recuerdos. Es por ello por lo que la instrucción multisensorial tiene mucha importancia. (Parra, 2010)

En lo expuesto anteriormente, se explica con claridad la necesidad de proporcionar a las y los estudiantes los elementos necesarios para que puedan reconstruir sus memorias adquiridas en el aula con más facilidad, el docente debe buscar las estrategias y técnicas para que los diferentes sentidos entren en función y logren el objetivo de la enseñanza, que es el aprendizaje significativo.

Por lo tanto, el aprendizaje debe convertirse en una experiencia positiva y agradable pues experiencias negativas y estresantes traen como consecuencia dificultades de tipo cognitivo; es por esto por lo que contenidos académicos abstractos, alejados de la realidad e irrelevantes traen como consecuencia la dificultad para mantener la atención de los estudiantes.

La curiosidad y la novedad, que son propuestas por la neuroeducación como un método adecuado de aprendizaje, también pueden ser aprovechados para la difusión de valores y principios entre las y los estudiantes, pues partiendo de situaciones que generen interés se puede producir el aprendizaje y práctica de estos, evitando de esta manera las grandes dificultades de: bullying, acoso, abuso sexual, entre otras.

\section{El acoso y el abuso sexual escolar}

El acoso de índole sexual podría definirse desde diferentes perspectivas, es así como se dice que: "El acoso sexual es la manifestación de una serie de conductas compulsivas de solicitud de favores sexuales dirigidas a un receptor y va contra su consentimiento." El acoso de índole sexual podría definirse desde diferentes perspectivas, es así como se dice que: "El acoso sexual es la manifestación de una serie de conductas compulsivas de solicitud de favores sexuales dirigidas a un receptor y va contra su consentimiento" (Díaz, 2014).

Puede entonces entenderse que el acoso sexual es una manifestación de conductas dirigidas a un individuo bajo la solicitud de favores de índole sexual, los mismos que 
atentan contra la víctima porque se producen sin su consentimiento generando diferentes tipos de trauma.

El acoso no es muy lejano a la definición de abuso sexual, pues en ambos casos las actitudes y comportamientos del victimario son similares como lo explica la Psicóloga María Calvente:

\begin{abstract}
Va desde la amenaza al engaño, la seducción y/o confusión. Podemos hablar de abuso siempre que el otro no quiera o sea engañado, (incluso dentro de la pareja). Es un acto que pretende dominar, poseer, cosificar a la persona a través de la sexualidad. Unas veces el agresor actúa desde la violencia explícita hacia la víctima, que se siente impotente, desprotegida, humillada. Otras veces, se vale de la confianza en él depositados para desde la cercanía de una relación afectiva, romper los límites de la intimidad e introducir elementos eróticos, (sobre todo en niñas y preadolescentes). Establece una relación confusa, irrumpiendo no sólo en su sexualidad, sino en el conjunto de su mundo afectivo y vivencial. En estos casos, el abuso no es sólo sexual, sino que también se da un abuso de confianza. (Calvente, 2009)
\end{abstract}

Como lo expresa el texto anterior el abuso sexual se extiende en varios campos, desde el engaño y seducción hasta la confusión que se puede provocar en otros sin que exista el consentimiento del contrario y provocando miedo, impotencia y sensación de desprotección, de lo cual el victimario se aprovecha para llevar a cabo sus más bajos instintos, para después utilizar la amenaza como un herramienta de extorsión que en gran parte de los casos ocasiona que no se den denuncias o incluso que se intente tapar los hechos para evitar capturar al perpetrador.

\title{
Método
}

A través de lo expuesto anteriormente se determinó que el sistema nervioso, fundamentalmente el cerebro tiene importancia trascendental en la conducta y aprendizaje de las y los estudiantes; el punto focal de este trabajo consiste en determinar la forma cómo la neuroeducación aplicada con el enfoque de disciplina militar puede generar cambios comportamentales en las y los estudiantes para que puedan reaccionar adecuadamente a situaciones de acoso y abuso sexual dentro de las instituciones educativas.

Los datos empíricos proporcionados por los estudiosos de la neuroeducación demuestran que: "La Neuroeducación puede influir de forma significativa en el proceso de detección e intervención de déficits en el aula; que puedan obstaculizar o disminuir distintas habilidades como la lectura, la escritura, el cálculo o aprendizaje, de manera temprana. Además de ayudar a "prevenir, reducir o mitigar todas aquellas consecuencias de vivir en ambientes estresantes y negativos o de constante amenaza, con lo que adquieren hábitos que influyen también de manera negativa en el desarrollo normal de sus cerebros" (Mora, 2013).

El texto anterior afirma que con la aplicación de la neuroeducación se puede lograr el desarrollo de habilidades como: lectura, escritura, cálculo y otros ámbitos; pero, también puede lograr disminuir las consecuencias de vivir en ambientes o situaciones negativos o de amenaza, motivando respuestas apropiadas por parte de las y los estudiantes.

Los elementos de disciplina militar, manejados de manera correcta pueden despertar 


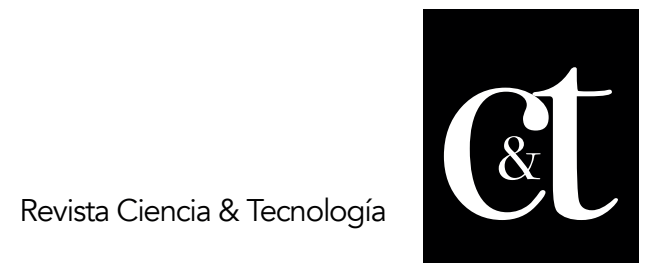

No. 18, 30 de abril de 2018

ISSN impreso: 1390 - 6321

la curiosidad en el cerebro de las niñas, los niños y adolescentes para activar el deseo de aprender, predisponiéndolos para la adquisición de nuevos conocimientos que, en este caso en particular, se concentra en el desarrollo de los valores como ejes transversales en la educación.

Cabe entonces la pregunta, ¿Te gustaría ser un héroe?, con seguridad la respuesta será afirmativa tanto en niños y niñas como en adolescentes, porque todos alguna vez sueñan con salvar a su país o por el reconocimiento que proporciona la sociedad ante la realización de un acto heroico, está proporcionado el primer elemento que genere interés o curiosidad.

De igual manera, muchos se preguntan el porqué del comportamiento distintivo de los militares, las actividades que realizan e incluso relacionan su trabajo únicamente con el manejo de armas o acciones violentas que terminan con la vida de los enemigos.

Sin embargo, debe considerarse que el rol del militar requiere del despliegue de una gran cantidad de valores para los que son comprometidos desde el mismo momento en que aceptan ser parte de la institución. El militar debe cumplir con obligaciones y deberes encaminados a lograr la grandeza de la Nación y la felicidad de los habitantes, por lo que los valores que desarrolla a lo largo de su carrera profesional son, entre otros: cohesión, disciplina, ética, honestidad, honor, lealtad y moral.

Las niñas, los niños y adolescentes se ven alienados por programas en los medios de comunicación e internet, que en muchas ocasiones difunden la práctica de antivalores que son cada vez considerados dentro de la normalidad y que convergen en situaciones de: bullying, casos e incluso abuso sexual dentro de las instituciones educativas.

Es necesario despertar interés en las y los estudiantes para lograr que el aprendizaje y práctica de valores y principios permitan su reacción ante las insinuaciones de tipo sexual con su respectiva denuncia; de tal manera que se evite el cometimiento de estos delitos.

La instrucción formal militar es uno de los aspectos que se manejaban como parte de la participación estudiantil y vinculación con la comunidad pues permitía desarrollar conceptos de disciplina, orden y liderazgo entre las y los estudiantes secundarios del Ecuador.

Se integra este importante factor a la educación por cuanto se puede comprobar que la instrucción militar fortalece tanto física como espiritualmente a los jóvenes, ayudando a la creación de hábitos disciplinarios que permiten el correcto funcionamiento de la sociedad, tanto en situaciones sociales cotidianas como en el caso de requerir reacción ante eventos fortuitos o desastres; así como ante las insinuaciones inadecuadas de índole sexual que se presenten interna o externamente a la institución educativa.

Es así como, la instrucción formal se convierte en un proceso educativo que permite desarrollar en las/los jóvenes el espíritu competitivo y la solidaridad en busca del cumplimiento de metas positivas, siendo un complemento de la educación secundaria para la formación de aptitudes de participación consciente y crítica de los problemas de la comunidad. 
Los valores que se desarrollan a través de la instrucción formal militar son: patriotismo, valores morales, valores cívicos, respeto, espíritu de cuerpo, honor, liderazgo entre otros; por lo tanto, se convierte en una necesidad que las/los estudiantes en algún momento de su desarrollo estudiantil se enfrenten a la instrucción de tipo militar.

\section{Aplicación del proyecto}

La instrucción formal militar es uno de los aspectos que se manejaban como parte de la participación estudiantil y vinculación con la comunidad pues permitía desarrollar conceptos de disciplina, orden y liderazgo entre las y los estudiantes secundarios del Ecuador

Se integra este importante factor a la educación por cuanto se puede comprobar que la instrucción militar fortalece tanto física como espiritualmente a los jóvenes, ayudando a la creación de hábitos disciplinarios que permiten el correcto funcionamiento de la sociedad, tanto en situaciones sociales cotidianas como en el caso de requerir reacción ante eventos fortuitos o desastres; así como ante las insinuaciones inadecuadas de índole sexual que se presenten interna o externamente a la institución educativa.

Es así como, la instrucción formal se convierte en un proceso educativo que permite desarrollar en las/los jóvenes el espíritu competitivo y la solidaridad en busca del cumplimiento de metas positivas, siendo un complemento de la educación secundaria para la formación de aptitudes de participación consciente y crítica de los problemas de la comunidad.

Los valores que se desarrollan a través de la instrucción formal militar son: patriotismo, valores morales, valores cívicos, respeto, espíritu de cuerpo, honor, liderazgo entre otros; por lo tanto, se convierte en una necesidad que las/los estudiantes en algún momento de su desarrollo estudiantil se enfrenten a la instrucción de tipo militar.

La fase de Instrucción formal militar consta de las siguientes etapas:

1. Socialización y práctica de valores cívicos.

2. Socialización de valores y principios personales.

3. Instrucción formal militar

4. Preparación física

\section{Socialización y práctica de valores cívicos}

Los actos cívicos son parte de la tradición escolar, los mismos que deben mantenerse y convertirse en un espacio para la participación de los estudiantes; quienes a través de este tipo de actividades se convierten en ciudadanos: críticos, capaces, propositivos que permitan construir una sociedad con alto nivel de convivencia adecuada.

Inculcar valores cívicos en los estudiantes no sólo es socializar el amor por la Patria, también significa generar respeto por los Símbolos Patrios y desarrollar valores que los estudiantes pueden aplicar a lo largo de sus vidas; siendo el principal el respeto hacia las personas que los rodean y hacia sí mismos.

De igual manera, los estudiantes generan sentimientos de orgullo por su Patria y 
nacionalidad, conoce su historia nacional a través de la difusión de fechas cívicas y aprende a reconocer los errores $y$ aciertos del pasado para proyectarse adecuadamente al futuro.

\section{Socialización de valores y principios}

Los valores y virtudes personales y sociales son la marca que tiene cada uno de los individuos que forman el sistema social. Al vincular lo mencionado al ámbito militar, el objetivo fundamental es encausar a los estudiantes por el camino de la verdad, la rectitud, el bien y las buenas costumbres, para que ahora y en el futuro sean mujeres y hombres de honor, ciudadanos responsables y patriotas, capaces de servir a la Nación y con disposición para entregar su vida en el caso de que la Patria lo requiera.

Los valores y principios que se desarrollarán a lo largo del Programa con la opción instrucción militar serán enfocados a evitar y denunciar los delitos sexuales, siendo estos valores los siguientes:

- Puntualidad.

- Obediencia

- Disciplina

- Patriotismo

- Responsabilidad

- Lealtad

- Respeto

- Justicia

- Camaradería

- Integridad

- Confianza en sí mismo

- Firmeza

- Bondad

- Franqueza

- Honradez

- Modestia

- Paciencia

- Generosidad

- Gratitud

- Constancia

- Educación

- Eficiencia

- Identidad e individualidad

- Libertad

- Liderazgo positivo

- Modestia

- Optimismo

- Perseverancia

- Cooperación

- Discreción

- Empatía

- Entusiasmo

- Igualdad

- Prudencia 
- Autocontrol

- Serenidad

- Sencillez

- Espontaneidad

- Tolerancia

- Integridad

- Comprensión

\section{Conclusiones}

Los estudiantes conocen instalaciones militares por medio de visitas guiadas y se ponen en contacto con los militares quienes dan a conocer mensajes sobre el trabajo que se realiza y lo que este requiere, así como las características de personalidad y actitudes que se requiere en los jóvenes.

De igual manera se puede plantear una convivencia para que las y los jóvenes sientan en carne propia las experiencias de tipo militar y reciban charlas sobre lo que pueden alcanzar actuando de forma adecuada y denunciando los delitos sexuales que se cometan contra ellos.

\section{Referencias bibliográficas}

Calvente, M. (11 de noviembre de 2009). Rompamos el Silencio. Obtenido de Si sufriste abuso sexual: http://www.abusosexualhablemos.com/index.php?option $=$ com content\&task $=\mathrm{v}$ iew\&id $=7 \&$ Itemid $=17$

García, A. (2017). Todo sobre la neuroeducación: Qué es, para qué sirve, y cómo aplicarla en la escuela y en casa. Obtenido de https://blog.cognifit.com/es/neuroeducacion-que-es-y-para-que-sirve/

González Tapia, C. (2016). Una propuesta de aplicación a la enseñanza de la lengua materna. Tesis doctoral, Universidad Complutense de Madrid. Obtenido de https://eprints.ucm.es/35929/1/T36890.pdf

Damasio, A. (2006). El error de Descartes. Madrid: Editorial Crítica.

Díaz, J. (3 de noviembre de 2014). El acoso sexual, definición y sus características. Obtenido de Prezi: https://prezi.com/xaezjqqjuvmb/el-acoso-sexualdefinicion-ysus- consecuencias/

Mora, F. (2013). Neuroeducación. Madrid: Alianza Editorial.

Parra, Z. (2010). Actividades y experiencias que propician la plasticidad cerebral de los estudiantes. Bogotá: Universidad Distrital Francisco José Caldas.

Paterno, R. (03 de marzo de 2015). Neuroeducación: Hoy. UM - Tesauro 11(8). Obtenido de Neuroeducación: Hoy: https://www.unimoron.edu.ar/static/media/doc_48d7f32a8a6511e48e05080 0279c6c15_o.pdf 